\title{
Implantação da Política Nacional dos Resíduos Sólidos no Norte Goiano
}

\author{
Deployment of the National Policy of solid waste in north Goianian
}

\author{
Nilma Silvania Izarias ${ }^{1}$, Bárbara Izarias Barbosa², Maria Rosa Izarias ${ }^{3}$ e Vilma França Monteiro ${ }^{4}$ \\ 1,2,4 Instituto Federal de Ciência e Tecnologia de Goiás /Campus Uruaçu Brasil \\ nilmaizarias@hotmail.com; bizariasb@hotmail.com; vilma.ifg@gmail.com \\ ${ }^{3}$ Universidade Paulista (UNIP). Brasil \\ mariarosa.mri@gmail.com
}

\begin{abstract}
Resumo
O presente estudo investigou o processo de implantação da Lei 12.305/10, a qual obriga os municípios brasileiros dispor adequadamente seus resíduos sólidos. Busca entender a sua implantação, no centro-norte goiano, traçando pontos em comuns das dificuldades encontradas pelos municípios para a gestão adequada dos resíduos sólidos. Este estudo envolveu 21 municípios, realizando-se observação in loco e entrevista a moradores e gestores ambientais dos municípios. Foi possível perceber nos municípios visitados e nas pesquisas aos demais municípios consorciados, que todos ainda dispõem seus resíduos na forma de vazadouro à céu aberto (Lixão). Não conseguiram atender aos prazos estipulados pela lei 12.305/10 principalmente pelo excesso de exigências impostas para captação de recurso, pela morosidade do governo Federal para aprovação dos projetos e liberação dos recursos, e pela cultura brasileira de protelação dos prazos. É possível aferir que, no momento de implantação da referida lei a maior dificuldade que os municípios enfrentará, será a mudança de cultura do cidadão.
\end{abstract}

Palavras-chave: Gestão Pública. Resíduos Sólidos Urbanos. Lei 12.305/10.

\begin{abstract}
The present study investigated the implementation process of Law 12.305 / 10, which obliges Brazilian municipalities properly dispose their solid waste. Seeks to understand its implementation, in north-central of Goiás, tracing common points on the difficulties encountered by municipalities for proper solid waste management. This study involved 21 municipalities, carrying out on-site observation and interview residents and environmental management of municipalities. It could be observed in the municipalities visited and in the research consortium the other municipalities that everyone still has their waste in the form of the open dump (Dump). They failed to meet the terms established by Law 12,305/10 mainly due to the excess of requirements imposed for resource capture, the slow pace of the federal government for approval of projects and disbursement of funds, the Brazilian culture of postponement of deadlines. It's possible check that at the time of implementation of the Act the greatest difficulty that municipalities will face, will be the change in citizen culture.
\end{abstract}

Keywords: Public management. Solid Urban Waste. Law 12.305/10. 


\section{Introdução}

Um dos grandes problemas ambientais da atualidade é a gestão dos resíduos sólidos, que têm aumentado de forma insustentável, diante do crescimento populacional e de seu exagerado consumismo (FERRI, CHAVES e RIBEIRO et al, 2015). Segundo dados do Instituto Brasileiro de Geografia e Estatística, em 2010, cerca de $85 \%$ da população brasileira estava concentrada em áreas urbanas (IBGE, 2010).

Assim, para Ferri, Chaves e Ribeiro et al (2015) o crescimento econômico e o aumento da população nas cidades acarretou no acréscimo da geração de Resíduos Sólidos Urbanos (RSU).

No ano de 2014, segundo o relatório da Associação brasileira de empresas de limpeza pública e resíduos especiais, foi gerado no Brasil cerca de 78,6 milhões de toneladas de lixo, o que representa um aumento de $2,9 \%$ em relação ao ano de 2013, índice superior à taxa de crescimento populacional no país no período, que foi de $0,9 \%$ (ABRELPE, 2014).

Este crescimento populacional impactou a infraestrutura de serviços urbanos, entre eles a gestão dos resíduos sólidos. O descarte dos resíduos sólidos urbanos passou a ser um problema público, resultando nos "lixões". Nesses locais não há nenhum controle e tratamento das dispersões de chorume e gases de efeito estufa, trazendo sérios impactos ambientais. $\mathrm{O}$ "que motivou o governo a promover estrutura legal para impulsionar um aumento na capacidade de manejar e gerenciar esses resíduos" (FERRI, CHAVES e RIBEIRO et al, 2015).

A grande maioria dos municípios brasileiros tem carência de sistemas de saneamento, dificultando o desenvolvimento e conservação ambiental. Pesquisa Nacional de Saneamento Básico (PNSB) publicada pelo IBGE (2008) mostra que, 50,8\% dos municípios brasileiros não destinam lixo em aterro sanitário. Em Goiás era alarmante a forma que os municípios destinavam o lixo, sendo que $50,4 \%$ depositavam os seus resíduos sólidos em lixões, $17,47 \%$ em aterros controlados e apenas 3,25\% em aterro sanitário, no ano de 2005. Já em 2009, esse percentual tinha se alterado para 59,34\% dos municípios descartavam seus resíduos em lixões, 31,30\% destinavam em aterros controlados e 3,65\% faziam a disposição de seus resíduos em aterro sanitário.

O impacto de tudo isso recai sobre a saúde pública, onde a maior parte (dois terços) das internações hospitalares de crianças registradas no Brasil decorre da ausência ou da precariedade dos serviços de saneamento (SILVA, 2009).

Segundo Werthein (2004), doenças relacionadas à água estão entre as mais frequentes causas de morte em todo o mundo e afetam principalmente países em desenvolvimento e crianças menores de cinco anos, sendo que o consumo de água contaminada e a falta de saneamento matam mais de 2,9 milhões de pessoas por ano. Os resíduos lançados em lixões aumentam cada vez mais a degradação dos recursos naturais, comprometendo a saúde da população. O manejo correto de resíduos sólidos urbanos ajuda na manutenção da qualidade ambiental e da saúde da população (BROLLO et al, 2009).

De acordo com a Lei 6.938/81, considera-se poluente "toda e qualquer forma de matéria ou energia que, direta ou indiretamente, causam poluição ao meio ambiente, nos estados líquido, sólido ou gasoso" (BRASIL, 1981). Assim, o lixo também deve ser considerado como poluente.

Medidas, de redução de gases estufa, de preservação do Meio Ambiente e da saúde pública, vem oportunamente, ao encontro à questão. Assim dar um destino adequado aos detritos de uma cidade, torna-se uma ação de interesse tanto da administração pública Municipal, Estadual e Federal, assim como de instituições de ensino, de cidadãos locais e de todo o planeta (DIAS, 2010; FERRI, CHAVES e RIBEIRO et al, 2015).

A questão da destinação adequada do lixo e tudo o que ela engloba, embora carecesse de regulamentação específica, não estava desregulamentada, pois já havia leis e normas regulamentadoras como a Lei 6.938/81 (Política Nacional do Meio Ambiente), a Lei 9.605/98 (Lei dos Crimes Ambientais), e a Lei 11.445/2007 (Lei do Saneamento Básico), entre outras. Como o lixo é questão ambiental, há uma série de normas e resoluções do Conselho Nacional de Meio Ambiente (CONAMA), normas de natureza administrativa, sem contar com o Licenciamento Ambiental, com Estudo de Impacto Ambiental/Relatório de Impacto Ambiental (EIA/RIMA), requisito constitucional para implementação de qualquer atividade potencialmente degradadora.

Buscar soluções para problemas relacionados aos resíduos sólidos urbanos nem sempre é fácil. Ficando clara a necessidade de regulamentação específica. A nova lei, promulgada em 02 de agosto de 2010, depois de quase 20 anos de tramitação, representa uma enorme conquista para a sociedade brasileira, e de acordo com o capitulo III, artigo 25 da lei 12.305/2010, o qual trata das responsabilidades, dispõe que: "O poder público, o setor empresarial e a coletividade são responsáveis pela efetividade das ações voltadas para assegurar a observância da Política Nacional de Resíduos Sólidos, das diretrizes e demais determinações estabelecidas nesta lei e em seu regulamento" (BRASIL, 2010).

O envolvimento de instituições de ensino com as administrações locais tem se mostrado uma excelente parceria, provocando uma ruptura de hierarquia quanto ao poder e facilitando uma colaboração entre sociedade e administração pública, mostrando-se um importante instrumento para a politização social e atingindo novos patamares de consciência pública e ambiental.

Este estudo deve ser entendido como um instrumento indutor do desenvolvimento político, social, econômico e ambiental. A relevância do tema apresentado-justifica a necessidade de um estudo detalhado da Lei, a qual institui a Política Nacional de Resíduos Sólidos e, uma investigação quanto ao processo de implantação e imple- 
mentação da referida lei em municípios do norte goiano.

Nesse sentido, esta pesquisa realizada no ano de 2014, buscou diagnosticar e discutir o panorama da aplicação da lei 12.305/210 que institui a Política Nacional de Resíduos Sólidos, dispondo sobre seus aspectos sociais, políticos e econômicos decorrentes da gestão de resíduos sólidos urbanos, verificando quais são os pontos comuns das dificuldades que os municípios do centro-norte goiano estão enfrentando para a sua aplicação.

\section{Materiais e Métodos}

O presente estudo envolveu 21 municípios do centro-norte goiano, atingindo um total estimado para o ano de 2015 de 290.718 habitantes (IBGE, 2015). Destes, foram efetuadas visitas in loco nos municípios de Uruaçu, Niquelândia, Campinorte, Ceres e Rubiataba. Nos demais municípios, as pesquisas foram bibliográficas, por serem municípios que participam de consórcios intermunicipais e por apresentarem realidades semelhantes.

Nas visitas in loco realizou-se a caracterização das Centrais de Disposição de Resíduos Sólidos (CDRS), entrevistas a moradores e secretários de Meio Ambiente (SMMA), verificando sobre a aplicação das legislações pertinentes. Aliando-se a este levantamento realizouse revisões bibliográficas referentes à Lei 12.305/2010 e suas diretrizes, as normas regulamentadoras da disposição dos resíduos sólidos, aterro sanitário, chorume em área de disposição de resíduos sólidos.

O tratamento dos resultados obtidos e interpretação dos dados foram realizados a partir da análise dos questionários aplicados, das visitas in loco, e das conversas com moradores. Segundo Gil (1999) a "interpretação dos dados pelo pesquisador é necessária para que possa ultrapassar a descrição, obtendo questionamentos sobre o assunto, buscando e acrescentando durante a pesquisa as possíveis explicações, dúvidas, configurações e efeitos".

Portanto, neste estudo foram utilizados como procedimentos metodológicos a pesquisa bibliográfica, a pesquisa de campo, a observação e entrevista a moradores e gestores ambientais dos municípios, além da análise e interpretação das informações.

\section{Resultados e Discussões}

O presente estudo é resultado de uma pesquisa realizada em 21 municípios do centro-norte goiano (Tabela 1) dentre os quais ocorreram visitasin loco em Uruaçu, Niquelândia, Campinorte, Ceres e Rubiataba.

Os quatro últimos municípios fazem parte de consórcios intermunicipais. A cidade de Campinorte consorcia um aterro sanitário com os municípios de Alto Horizonte e Nova Iguaçu (Consórcio Intermunicipal Rio dos Bois). Rubiataba e Ceres consorciam com mais 14 municípios: Rialma, Carmo do Rio Verde, Nova Glória, Nova América, Rianápolis, Ipiranga de Goiás, Itapuranga, Uruana, Heitoraí, Guaraíta, São Patrício, Jaraguá, São Francisco de Goiás, Jesúpolis (Consórcio Intermunicipal de Desenvolvimento da Região do Vale do São Patrício - CIDERSP - GO) conforme demonstra a Tabela 1 e figura 01.

Demajorovic et al. (2012) afirmam que a análise entre aumento da renda e poluição é intuitiva, pois indivíduos com maior renda consomem mais e, portanto, geram, inevitavelmente, mais poluição. Para Johnstone; Labonne (2004), a quantidade de resíduos que um habitante produz pode ser utilizada como indicativo de seu poder aquisitivo.

Analisando o Indice de Desenvolvimento Humano Municipal (IDHM), nos municípios pesquisados está entre 0,6 e 0,7 considerando que "o indeal é um número próximo ao 1 (um)” (PNUD, 2015), percebe-se que estes municípios perecisam melhorar o desenvolvimento em três dimensões: longevidade, educação e renda. A renda impacta no consumo e produção de lixo. A disposição adequada do lixo impacta diretamente na saúde, consequentemente na longevidade.

Realizou-se um levantamento do perfil acadêmico dos prefeitos e secretários dos municípios visitados. Nenhum prefeito ou secretário de meio ambiente possui formação na área ambiental. Buscam estudar e entender dos assuntos que estão relacionados com a sua secretaria. Alguns secretários mostraram-se entendedores das políticas públicas direcionadas à problemática em estudo. Todas as prefeituras visitadas contam com a cooperação de equipe técnica multidisciplinar especializada. Como equipe técnica especializada, citaram o nome de uma organização não governamental, sediada na capital Goiânia, que presta assessoria à várias prefeituras do interior do Estado.

Em visita in loco, observou-se os itens descritos na tabela, e em conversa com os secretários municipais, confirmou-se os dados apresentados na tabela 02 .

A escolha da atual área para instalação das centrais, não obedeceu às normas ambientais. Os atuais SMMA desconhecem a existência de um estudo de impactos ambientais (EIA) do local onde dispõem os resíduos urbanos, na atualidade, o "Lixão". Os SMMA responderam que "Antigamente não existia a preocupação com o Meio Ambiente, como se tem atualmente." Imaginam que o local escolhido para implantação da CDRS, foi a disponibilidade do terreno pela prefeitura há mais de 10 ou 20 anos atrás. E, em alguns casos a cidade cresceu ficando muito próximas à CDRS.

Observou-se em todas os CDRS a presença de pessoas trabalhando (Tabela 02), no recolhimento de materiais que tenham algum valor comercial (Figuras 02 e 03).

A preocupação com estes trabalhadores, se dá em função das más condições laborais, da falta de qualidade de vida, de bem-estar físico, mental e social, bem como dos riscos aos quais estão sujeitos os catadores 
Tabela 1 - Municípios pesquisados

\begin{tabular}{|c|c|c|}
\hline \multicolumn{3}{|c|}{ Municípios que não fizeram consórcio } \\
\hline Cidade & População $\left(2010^{\left.1 / 2015^{2}\right)}\right.$ & $\mathrm{IDHM}^{3}$ \\
\hline Niquelândia & $42.361 / 45.243$ & 0,715 \\
\hline Uruaçu & $36.929 / 39.483$ & 0,737 \\
\hline Total da população & \multicolumn{2}{|l|}{79.290 / 84.726} \\
\hline \multicolumn{3}{|c|}{ Municípios que compõe o Consórcio Intermunicipal Rio dos Bois } \\
\hline Campinorte & $11.111 / 12.071$ & 0,688 \\
\hline Alto Horizonte & $4.505 / 5.470$ & 0,719 \\
\hline Nova Iguaçu de Goiás & $2.826 / 2.944$ & 0,655 \\
\hline Total da população & $18.442 / 20.485$ & \\
\hline \multicolumn{3}{|c|}{ Municípios que compõe o CIDERSP ${ }^{4}$} \\
\hline Ceres & $20.722 / 21.909$ & 0,775 \\
\hline Carmo do Rio Verde & $8.928 / 9.671$ & 0,713 \\
\hline Heitoraí & $3.571 / 3.731$ & 0,694 \\
\hline Guaraíta & $2.376 / 2.268$ & 0,687 \\
\hline Ipiranga de Goiás & $2.844 / 2.940$ & 0,699 \\
\hline Itapuranga & $26.125 / 26.639$ & 0,726 \\
\hline Jaraguá & $41.870 / 46.790$ & 0,699 \\
\hline Jesúpolis & $2.300 / 2.444$ & 0,649 \\
\hline Nova América & $2.259 / 2.358$ & 0,678 \\
\hline Nova Glória & $8.508 / 8.575$ & 0,681 \\
\hline Rialma & $10.523 / 10.969$ & 0,727 \\
\hline Rianápolis & $4.566 / 4.788$ & 0,693 \\
\hline Rubiataba & 18.915 / 19.832 & 0,719 \\
\hline São Francisco de Goiás & $6.120 / 6.341$ & 0,651 \\
\hline São Patrício & $1.991 / 2.062$ & 0,693 \\
\hline Uruana & $13.826 / 14.190$ & 0,703 \\
\hline Total da população & \multicolumn{2}{|l|}{$175.444 / 185.507$} \\
\hline Total geral da população pesquisada & \multicolumn{2}{|l|}{$273.176 / 290.718$} \\
\hline
\end{tabular}

${ }^{1}$ Dados do IBGE (2010); 2 População estimada para 2015 de acordo com Diretoria de Pesquisa (DPE- Coordenação de Populações e Indicadores Sociais - COPIS) Fonte: IBGE Cidades (2015); ${ }^{3}$ IDHM - Índice de Desenvolvimento Humano Municipal ( 2010) Fonte: IBGE Cidades (2015). ${ }^{4}$ CIDERSP - Consórcio Intermunicipal de Desenvolvimento da Região do Vale do São Patrício

Tabela 02 - Detalhamento das observações nas visitas às CDRS

\begin{tabular}{l|l|l|l|l}
\hline Município & Uruaçu & Campinorte & Rubiataba & Ceres \\
\hline $\begin{array}{l}\text { *Distância média dos } \\
\text { corpos d'água superficial }\end{array}$ & $1000 \mathrm{~m}$ & $500 \mathrm{~m}$ & $2000 \mathrm{~m}$ & $300 \mathrm{~m}$ \\
\hline $\begin{array}{l}\text { *Distância média de } \\
\text { residências; }\end{array}$ & $2000 \mathrm{~m}$ & $400 \mathrm{~m}$ & $2500 \mathrm{~m}$ & $1000 \mathrm{~m}$ \\
\hline $\begin{array}{l}\text { **Presença } \\
\text { trabalhadores }\end{array}$ & 40 pessoas & 6 pessoas & 6 pessoas & 5 pessoas \\
\hline $\begin{array}{l}\text { Forma de disposição dos } \\
\text { RS. }\end{array}$ & $\begin{array}{l}\text { Compactados e e } \\
\text { "Aterrados". }\end{array}$ & $\begin{array}{l}\text { Queimados e } \\
\text { aterrados }\end{array}$ & Aterrados & $\begin{array}{l}\text { Compactados e } \\
\text { Aterrados }\end{array}$ \\
\hline
\end{tabular}

*Valores médios. ${ }^{* *}$ valores informados pelos gestores municipais 


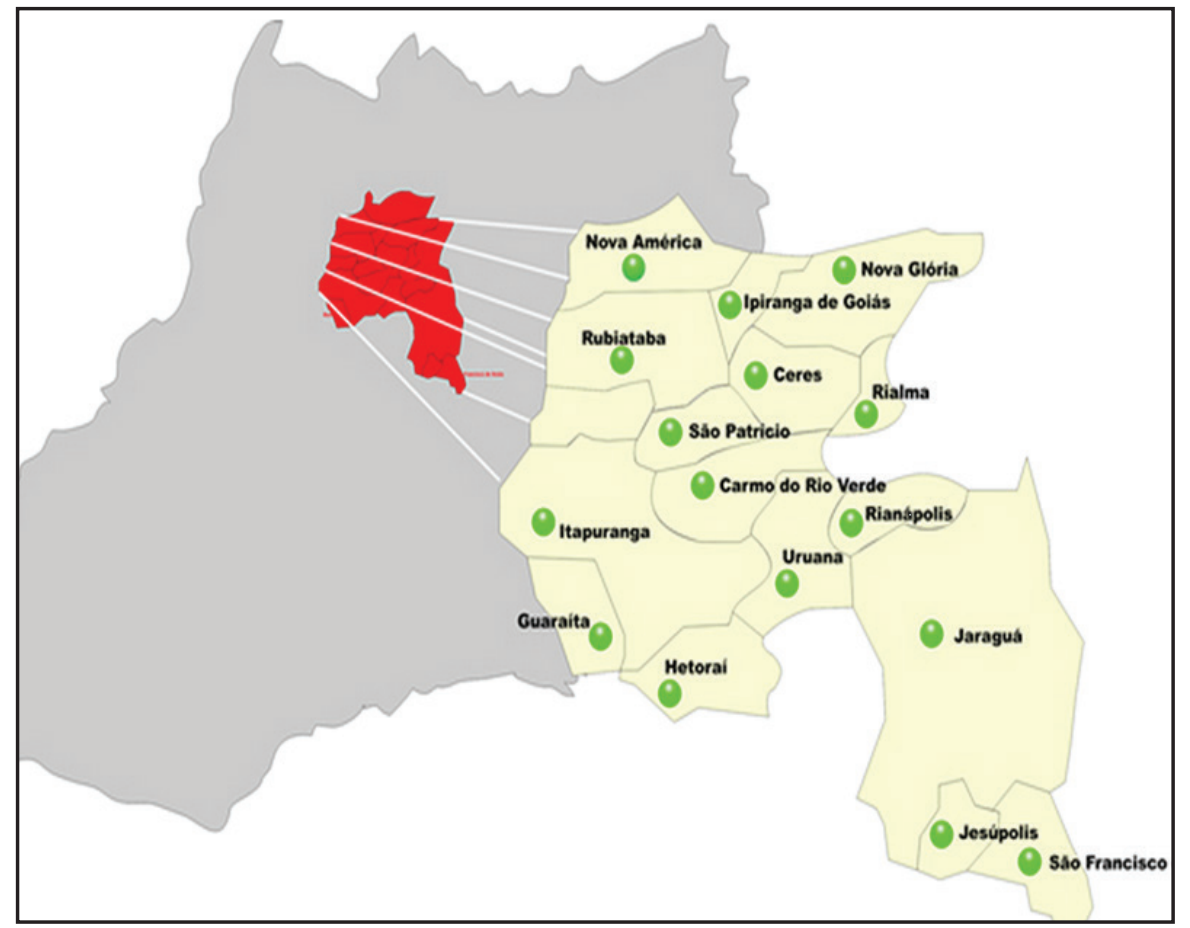

Figura 01 - Mapa com os Municípios que compõe o CIDERSP. - Municípios pesquisados e integrante de Consórcios Intermunicipais

Fonte: CIDERSP-GO, 2014

de materiais recicláveis, principalmente pelo contato direto com diversos resíduos provenientes das diversas atividades humanas. Estas más condições são agravadas pela exposição ao sol, calor e poeira, ampliando os riscos de aparecimento ou agravamento de doenças de pele, renais, cardíacas e respiratórias dentre outros (CORDEIRO, et al 2012).

Os acidentes e riscos ocupacionais relacionados à saúde do trabalhador são frequentes, principalmente, segundo Cordeiro, et al (2012), cortes e perfurações com vidros e outros objetos pontiagudos, como: espinhos, pregos, agulhas de seringas e espetos são responsáveis por corriqueiros acidentes envolvendo trabalhadores

As prefeituras não fornecem nenhuma ajuda de custo aos trabalhadores. As prefeituras de Uruaçu, Rubiataba e Ceres, afirmaram que todos os trabalhadores recebem os Equipamentos de Proteção Individual (EPI's)

necessários à sua proteção como, botas, luvas e máscaras. In loco observou-se que pouquíssimos trabalhadores utilizavam EPI, no máximo utilizavam luvas. Em conversas, afirmaram que, "a bota de plástico e a máscara aumentam o calor, por isso não as utilizam. As luvas às vezes se utiliza, mas pouco adianta". Cerca de 10 entrevistados mostraram as mãos cortadas ou perfuradas no manuseio dos resíduos. Em nenhum momento o pesquisador percebeu uma preocupação com a insalubridade física e de saúde dos trabalhadores.

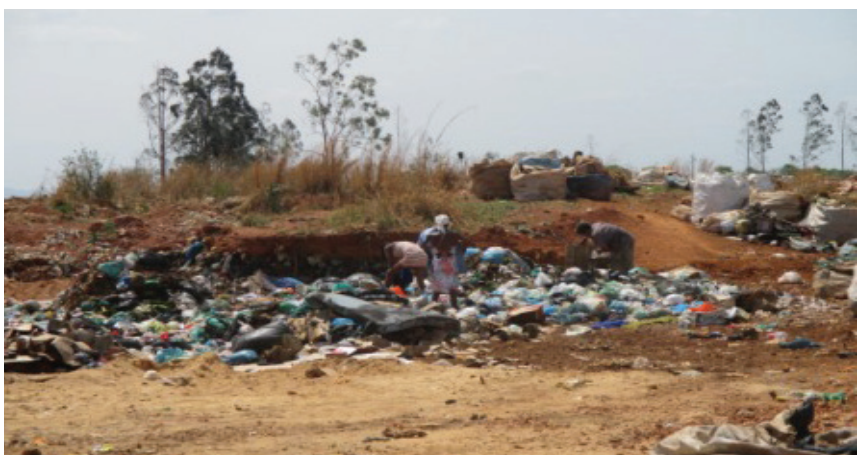

Figura 02 - Catadores de lixo trabalhando sem nenhuma proteção. Município de Uruaçu-GO

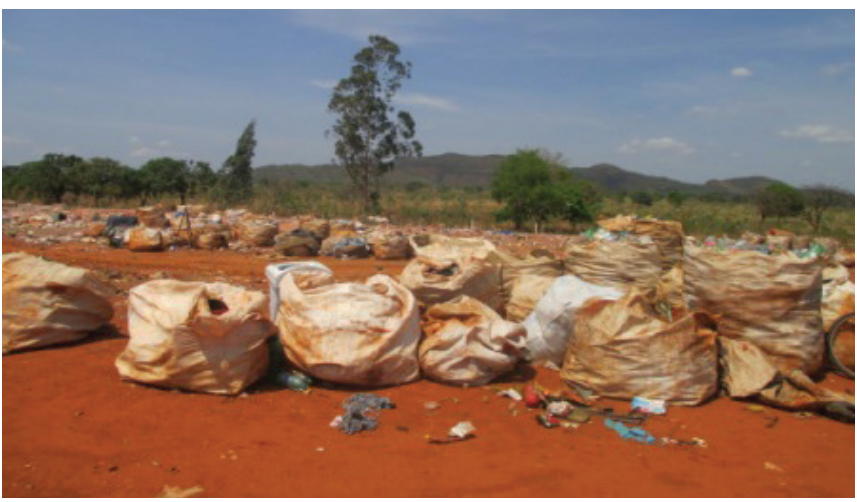

Figura 03 - Material reciclável retirado do lixão de Uruaçu 
Em visita à CDRS de Uruaçu observou-se que os trabalhadores levam uma marmita com o seu alimento. Não há um local apropriado com uma mínima higienização e conforto para realizar refeições. Percebeu-se que eles apenas paravam os afazeres para almoçar, a única água que tinham era da garrafa térmica, que levaram de casa para matar a sede. Foram encontradas famílias inteiras trabalhando, inclusive adolescentes.

Todos os municípios visitados dispõem seus resíduos sob a forma de Vazadouro a Céu Aberto (Lixão). Para os SMMA, atualmente é a forma possível de dispor os resíduos sólidos da cidade. O lixo é disposto em valas, amontoados e, periodicamente compactados, recebendo em seguida uma cobertura de terra (Tabela 02). Às vezes ocorrem queimadas do lixo, provocadas ou espontâneas (Figura 04). Este tipo de disposição dos resíduos não apresenta nenhum cuidado ambiental. Por outro lado, a técnica de cobertura com terras é utilizada também pelos aterros sanitários. Os RSU recebem uma cobertura de solo de forma a isolá-los do meio ambiente, reduzindo a proliferação de vetores de doenças, e minimizando os fenômenos de erosão e infiltração (KÄMPF; SCHNEIDER; GIASSON, 1997).

Em observação in loco, percebeu-se que os municípios de Uruaçu, Ceres e Rubiataba mantém no local máquinas para remoção, compactação e aterramento dos resíduos, mostrando-se preocupados com a proliferação de vetores de doenças (Figura 05 e 06).

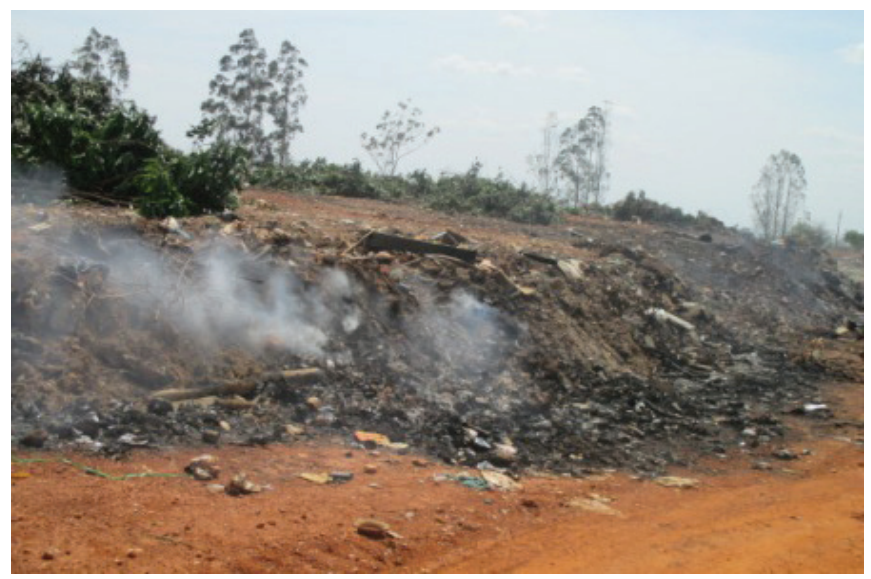

Figura 04 - Queimada de lixo no lixão de Uruaçu

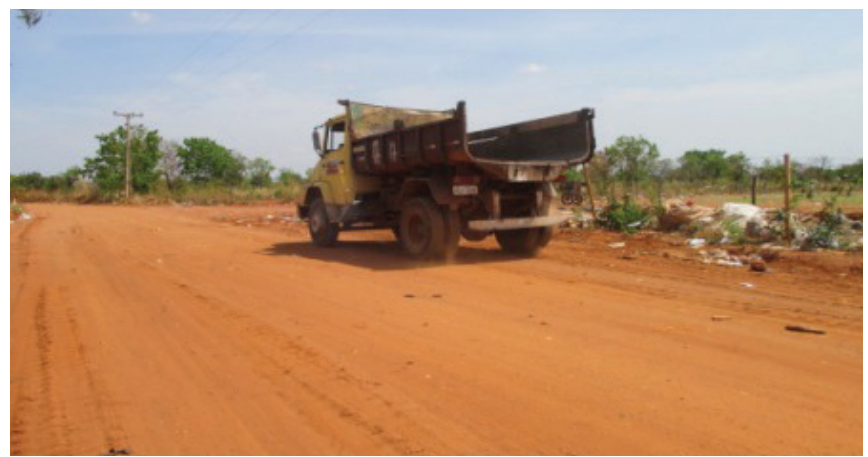

Figura 05 - Máquinas trabalhando no lixão de Uruaçu

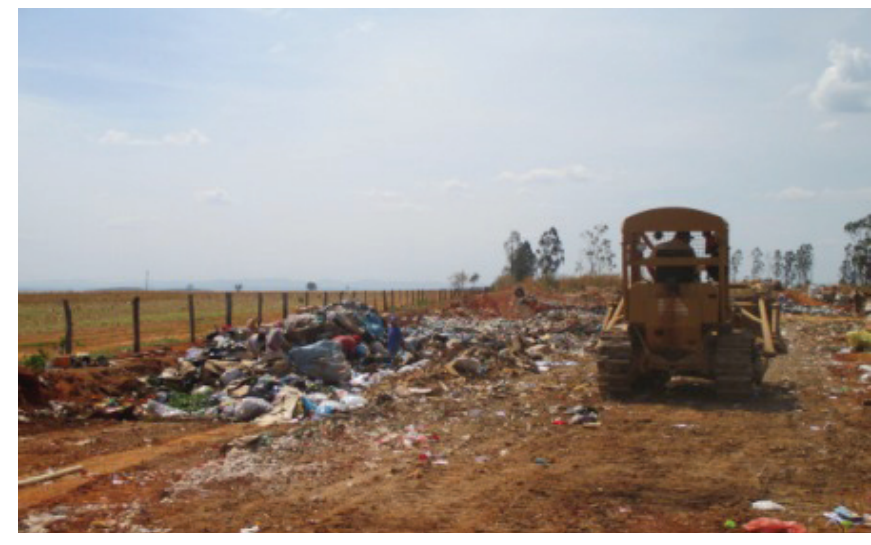

Figura 06 - Máquinas trabalhando no lixão de Uruaçu

Na atual área onde ocorre a disposição dos resíduos sólidos, não existiu um estudo de impactos ambientais (Tabela 3). A distância média dos corpos d'água superficial, varia de $300 \mathrm{~m}$ a $2000 \mathrm{~m}$ (Tabela 02). Atualmente as prefeituras não realizam um monitoramento da qualidade das águas na proximidade das CDRS. Empiricamente os SMMA acreditam que, pela proximidade de corpos d'água superficial e subterrânea, pode haver contaminação.

Para mitigar parte deste problema, são construídos curvas de nível, reduzindo possíveis contaminações em corpos d'agua superficiais. Os SMMA cogitaram a possibilidade de ocorrer um monitoramento das águas pela Companhia Saneamento de Goiás S/A (Saneago). Entretanto a Saneago monitora apenas as águas que têm influência direta nos locais de captação para abastecimento público (SANEAGO, 2015).

A preocupação com a possível poluição ocorre em função do chorume que é gerado no processo de decomposição da matéria orgânica e pela água da chuva, que passa pelas camadas físicas, químicas e microbiológicas dos resíduos, transferindo poluentes a partir de resíduos de água de percolação ou enchurrada (CHRISTENSEN; KJELDSEN, 1989).

Marques et al (2012), realizou um estudo em corpos d'água superficiais próximos a aterros sanitários e aterros controlados, e percebeu que a qualidade das águas não estavam satisfatórias em função das violações dos parâmetros fósforo, amônia, coliformes termotolerantes e da relação á Demanda Química e Bioquímica de Oxigênio (DQO/DBO) mesmo à montante do local de coleta. Em alguns locais estudados a situação foi mais crítica, pois o índice de qualidade da água (IQA) foi classificado como ruim em todos os pontos durante o período monitorado.

Quanto à existência dos projetos de gestão e gerenciamento dos resíduos, em todos os municípios estes projetos estão em construção ou em fase de aprovação. Nos municípios pertencentes aos consórcios intermunicipais, estes planos deverão ser construídos integrando todos os sistemas. Os municípios integrantes do consórcio CIDERSP - GO estão construindo um projeto de gestão 
agregando todos os municípios consorciados. O consórcio Rio dos Bois já está com o projeto pronto. Todos estes projetos, construído ou em construção, foram ou estão sendo feitos por equipe técnica multidisciplinar terceirizada. Mas os projetos de desativação do lixão só serão pensados após a construção da nova CDRS, em conformidade com os regulamentos vigentes.

No município de Niquelândia- Go, os resíduos são depositados em um aterro sanitário, localizado na BR 414, Km 3, mas em decorrência da má gestão na coleta, transporte e disposição dos resíduos sólidos urbanos, este aterro funcionou adequadamente por apenas 5 meses, de Junho a Novembro de 2010.

Atualmente a gestão deste aterro, assemelha-se a de um lixão. Ali são descarregadas muitas classes de resíduos impróprias para o local, de acordo com a NBR 10004/04, que classifica os tipos de resíduos.

Nesta investigação foi possível perceber que, os municípios estão com dificuldades para atendimento à lei 12.305/10, visto que, até Junho de 2014, nenhum dos 21 municípios pesquisados dispunham adequadamente seus resíduos urbanos.

A inexistência dos aterros sanitários é preocupação de todos os municípios, ficando claro na fala dos secretários que a falta de vontade política, equipe de trabalho capacitada, entendimento da legislação e excesso de burocracia são as principais dificuldades que impediram o não atendimento a lei 12.305/10 até o momento.
Os 21 municípios pesquisados é o reflexo de uma situação Nacional. Segundo a Abrelpe (2014), o Brasil pouco avançou no objetivo de acabar com os lixões. Em 2010, 42,4\% dos resíduos eram destinados inadequadamente, encaminhados para lixões ou para aterros controlados. Em 2014, essa porcentagem estava em 41,6\%, apresentando uma evolução de apenas 0,8 ponto percentual. Isto indica que pouco se fez entre a aprovação da lei $12.3015 / 10$, para acabar com os lixões.

Em 2014, de acordo com o relatório da Associação brasileira de empresas de limpeza pública e resíduos especiais, no Brasil havia um total de 1.559 municípios que usavam lixões a céu aberto, dentre eles Brasília e 1.775 que dispunham seus resíduos na forma de aterro controlado. Destes, o Centro Oeste de um total de 467 municípios, apenas 164 possuem aterro sanitário, 156 deles dispões seus resíduos na forma de lixões e 147 na forma de aterros controlados. Estes duas ultimas formas de disposição dos resíduos, despejam lixo em áreas abertas, contaminando o solo, o lençol freático e a água e, consequentemente, colocando em risco a saúde de sua própria população (ABRELPE, 2014).

Um dos secretários relatou algumas das dificuldades para atendimento das exigências feitas aos projetos, para liberação de recursos e construção dos aterros: “exigências são importantes e necessárias visando uma melhor qualidade do empreendimento, bem como uma maior probabilidade de que ocorra a execução dentro

Tabela 3 - Diagnóstico da atual Central de Disposição de Resíduos Sólidos (CDRS)

\begin{tabular}{|c|c|c|c|c|c|}
\hline Pergunta & Uruaçu & Campinorte & Rubiataba & Ceres & Niquelândia \\
\hline Tipo de CDRS & Lixão & Lixão & Lixão & Lixão & Aterro \\
\hline $\begin{array}{l}\text { Houve estudo prévio E.I. } \\
\text { para a CDRS atual? }\end{array}$ & Desc. & Não & Desc. & Desc. & Sim \\
\hline $\begin{array}{l}\text { Há possibilidade de } \\
\text { contaminação das águas nas } \\
\text { proximidades das CDRS? }\end{array}$ & Sim & Sim & Sim & Sim & Não \\
\hline $\begin{array}{l}\text { Há um monitoramento da } \\
\text { qualidade das águas } \\
\text { próximas as CDRS? }\end{array}$ & Não & Não & Desc. & Sim & Não \\
\hline $\begin{array}{l}\text { Há projetos para gestão } \\
\text { dos RSU? }\end{array}$ & EC & EA & $\mathrm{EC}$ & EC & Sim \\
\hline $\begin{array}{l}\text { Existe projeto para a } \\
\text { desativação do lixão, após } \\
\text { construção do aterro? }\end{array}$ & Não & Não & Não & Não & Desc. \\
\hline
\end{tabular}

Legenda: Desc. $=$ Desconhece; $\mathrm{EC}=$ Em construção; $\mathrm{EA}=$ Em aprovação 
das normas ambientais vigentes". No entendimento do excesso de burocracia, estão as Normas para a escolha da área e implantação dos aterros sanitários entre outras.

De acordo com Dante Ragazzi Pauli, da Associação Brasileira de Engenharia Sanitária e Ambiental, em entrevista à revista Época, para solucionar o problema dos resíduos sólidos urbanos é necessário fazer a lei sair do papel, "trabalhar a base, em cada município, antes de propor obras gigantescas". É preciso capacitar e "adequar os quadros das prefeituras, criar programas de assistência técnica", dentre outros. "E o município também precisa fazer sua parte" (CALIXTO, 2015).

Diante das exigências necessárias ao atendimento da Lei 12.3015/10, o melhor caminho encontrado pelas prefeituras foi a formação de consórcios intermunicipais. Os consórcios públicos são uma forma de gestão regulamentada pela lei 11.107/2005. Eles prestam serviço público de forma regionalizada. É incentivado e priorizado pela política nacional de resíduos sólidos, há uma inter-relação entre a lei 11.107/2005 e a lei da Política Nacional de Resíduos Sólidos. Atualmente constituem um marco regulatório do país. Os consórcios públicos têm inovado a gestão pública, que tem se fortalecido com a priorização de recursos federais, advinda da Lei 12.305/2010.

Após ultrapassar as barreiras acima descritas, uma das principais dificuldades de efetivação da lei, será a mudança de cultura dos cidadãos. Um programa de destinação correta do lixo perpassa pela vontade pública, ficando refém da ação consciente do cidadão. “Nenhum projeto terá sucesso sem a participação efetiva dos cidadãos, principalmente na separação do resíduo na origem," afirma o secretário da cidade de Ceres.

Elaborar o projeto para construção de um Aterro Sanitário não é simples, mas quando conseguem fazê-lo em tempo hábil encontram o problema da morosidade da máquina federal para aprovação ou desaprovação do projeto, com vistas à liberação dos recursos necessários para iniciar a execução das obras. Foi o que ocorreu no consórcio Rio do Bois. Fizeram o projeto com todo o estudo técnico, encaminharam ao Governo Federal no ano de 2012, e em janeiro de 2014 ainda aguardavam o parecer da análise.

A escolha da área para implantação dos aterros não é simples. Ocorreram estudos geológicos em vários lugares. O município que melhor atender às Resoluções que estabelecem critérios e diretrizes para o licenciamento de aterro sanitário de pequeno porte de resíduos sólidos urbanos (CONAMA № 404/2008), receberá o aterro sanitário. No consórcio Rio dos Bois a sede do aterro sanitário será na cidade de Nova Iguaçu. Ela receberá os Resíduos dos municípios de Campinorte e Alto Horizonte. Cada município terá uma estação de triagem e reciclagem e encaminhará ao aterro somente a parte do lixo que não puder ser aproveitada. $\mathrm{O}$ aterro será terceirizado e cobrará das prefeituras um valor por tonelada de lixo tratado (Tabela 04).

Considerando os estudos de Abrelpe (2014), em Goiás no ano de 2014, coletou - se a 6.278 Toneladas de lixo diariamente, para atender uma população de 6.523.222. Considerando que foi coletado em média $0,962 \mathrm{Kg}$ de resíduos sólidos urbanos por habitante por dia, podemos estimar que os municípios pesquisados quando as CDRS, estiverem em funcionamento, deixarão de ser disposto de forma inadequada, $279.670 .716 \mathrm{Kg}$ de lixo por dia.

Os municípios de Ceres e Rubiataba fazem parte de um consórcio Intermunicipal de Desenvolvimento da Região do Vale do São Patrício (CIDERSP-GO), este consórcio foi amplamente discutido entre equipe técnica, gestores e prefeitos. Foi a melhor alternativa encontrada por 16 municípios para atendimento as resoluções vigentes.

O CIDERSP-GO foi criado para os municípios atuarem juntos, com os objetivos de cortar gastos e dar destinação correta ao lixo, diz o secretário de Ceres. O Plano apresentado pelo CIDERSP-GO, indica a proposta de três aterros sanitários para a região, e serão instalados nas cidades de Jaraguá, Itapuranga e Rubiataba, que unindo-se aos municípios vizinhos irão tratar todos os RS gerados (Tabela 04).

Neste modelo de consórcio, só serão encaminhados aos aterros sanitários a parte dos resíduos que após triagem não houver possibilidade de reciclagem ou reaproveitamento.

Esta triagem será realizada por cooperativas de reciclagem, que já estão sendo criadas conforme regulamentação própria. No "início de funcionamento das cooperativas serão necessários o apoio logístico das prefeituras e outros que se fizerem necessários na forma de comodato" afirma um dos secretários.

Quanto aos resíduos infectocontagiosos, atualmente atendem ao código sanitário Estadual e encaminham à uma firma terceirizada de Anápolis, especializada no tratamento de resíduo. Em Ceres-Go, a aplicabilidade desta ação é eficiente, e é possível tem um controle rigoroso, pois a empresa que produz este tipo de resíduo só receberá o alvará de funcionamento anual se, apresentar o contrato de coleta e destinação adequado de seus resíduos".

Diante de tantas dificuldades os secretários municipais não conseguiram atender aos prazos determinados por lei, para 02 de agosto de 2014. “No modelo político brasileiro, mesmo quando há previsão na lei os administradores públicos não são obrigados e ou penalizados judicialmente pelo não atendimento às leis. No Brasil há uma cultura de protelar a aplicação de leis. É necessário um ação do ministério público para que se faça cumprir a lei, independente do mandato," afirma um dos secretários entrevistados.

Está previsto na referida Lei, que os municípios são responsáveis para viabilizar a aplicação da referida lei. O texto deixa claro que a omissão, por parte dos agentes públicos, pode resultar em sanções administrativas e até 
Tabela 04 - Futuro da Disposição dos Resíduos Sólidos Municipais

\begin{tabular}{|c|c|c|c|c|}
\hline Empreendimento & \multicolumn{4}{|c|}{ Localização do aterros sanitários conforme estudo da área. } \\
\hline \multirow[t]{2}{*}{$\begin{array}{c}\text { Aterro sanitário } \\
\text { individual }\end{array}$} & \multicolumn{2}{|c|}{$\begin{array}{l}\text { Uruaçu - } 39.483 \\
\text { hab/estimado } 2015 ;\end{array}$} & \multicolumn{2}{|l|}{$\begin{array}{c}\text { Niquelândia - } 45.243 \\
\text { hab/estimado } 2015\end{array}$} \\
\hline & \multicolumn{4}{|c|}{ Cidades atendidas dos consórcios } \\
\hline Consórcio & \multicolumn{3}{|c|}{ CIDERSP-GO } & Rio dos Bois \\
\hline Sede & Itapuranga & Jaraguá & Rubiataba & Nova Iguaçu \\
\hline $\begin{array}{r}\text { Cidades } \\
\text { integrantes }\end{array}$ & $\begin{array}{l}\text { Uruana } \\
\text { Heitoraí } \\
\text { Guaraita }\end{array}$ & $\begin{array}{l}\text { São Francisco } \\
\text { Jesúpolis }\end{array}$ & $\begin{array}{l}\text { Ceres } \\
\text { Rialma } \\
\text { Carmo do Rio Verde } \\
\text { Nova Glória } \\
\text { Nova América } \\
\text { Rianápolis } \\
\text { Ipuranga } \\
\text { São Patrício }\end{array}$ & $\begin{array}{l}\text { Campinorte } \\
\text { Alto Horizonte }\end{array}$ \\
\hline $\begin{array}{l}\text { Habitantes } \\
\text { estimados para } 2015\end{array}$ & 46.828 hab. & 55.575 hab. & 83.104 hab. & 20.485 hab. \\
\hline $\begin{array}{l}{ }^{*} \text { Quantidade de lixo } \\
\text { estimado, para } 2015 .\end{array}$ & $45,048.54$ & $53,463.15$ & $79,946.04$ & $19,707.57$ \\
\hline \multicolumn{3}{|c|}{ Total geral de habitantes - 290.718} & \multicolumn{2}{|c|}{ Total médio de lixo - 279.670.716 Kg / dia } \\
\hline
\end{tabular}

**Dados estimados, baseado-se na média per habitantes em Goiás para o ano de 2014, nos dados informados em ABRELPE (2014)

sanções penais. Mandatos podem ser cassados, recursos para municípios podem ser bloqueados e prefeitos podem ser forçados a ressarcir os cofres públicos. "Art. 52. A observância do disposto no caput do art. 23 e no $\S 2^{\circ}$ do art. 39 desta Lei é considerada obrigação de relevante interesse ambiental para efeitos do art. 68 da Lei n⿳0 9.605, de 1998, sem prejuízo da aplicação de outras sanções cabíveis nas esferas penal e administrativa".

De acordo com informações do Ministério do Meio Ambiente (MMA, 2015), em apenas quatro anos, a Política Nacional de Resíduos Sólidos produziu resultados significativos, destinando adequadamente quase a metade do lixo produzido no Brasil. Entre 2010 e 2014, o Governo Federal, por meio do Ministério do Meio Ambiente, Ministério das Cidades e Fundação Nacional de Saúde (Funasa) destinou R \$ 1,2 bilhão para implantar a PNRS e o número de municípios atendidos dobrou.

Percebe-se que no interior do Brasil, até o momento, após o vencimento do tempo previsto para a Lei 12.305/10, ainda se conseguiu avançar pouco no sentido de resolução do problema e implantação dos aterros. Um dos avanços foi a criação dos consórcio, estudo e obtenção do local adequado para construção do aterro e plano de gerenciamento. Falta muito ainda a ser feito.

\section{Conclusões}

A aplicação dessa lei visa o bem estar da população e a sustentabilidade, adotando tecnologias limpas como forma de reduzir os impactos ambientais. Dentro desta investigação, nenhum dos 21 município pesquisado em agosto de 2014 conseguiu atender a lei 12.305/10.

A inexistência dos aterros sanitários é preocupação de todos os municípios, e que a falta de vontade política, equipe de trabalho capacitada, entendimento da legislação e excesso de burocracia são as principais dificuldades que impediram o não atendimento a lei.

Considera-se que a obrigatoriedade de atendimento a uma lei perpassa um mandato político, pois esta muda periodicamente interferindo no desenvolvimento das políticas públicas. 


\section{Agradecimento}

Os autores agradecem ao Gestores Municipais pelas informações concedidas, ao Conselho Nacional de Desenvolvimento Científico e Tecnológico - CNPq e ao Instituto Federal de Ciência e Tecnologia de Goiás IFG Campus Uruaçu pelo apoio financeiro e logístico concedido respectivamente.

\section{Referências}

ABRELPE - Associação brasileira de empresas de limpeza pública e resíduos especiais. Panorama dos resíduos sólidos no Brasil, 2014. Disponível em: <http://www. abrelpe.org.br/Panorama/panorama2014.pdf $>$ Acesso em 23-09-2015.

BRASIL, Política Nacional do Meio Ambiente - Lei 6.938, de 31 de agosto de 1981. Brasília, DF: Congresso Nacional. Disponível em: <http://www.planalto.gov.br/ ccivil_03/leis/16938.htm>. Acesso em 30 de março de 2013.

BRASIL, Política nacional de resíduos sólidos - Lei n. 12.305, de 2 de agosto de 2010. [recurso eletrônico]. -2. ed. - Brasília: Câmara dos Deputados, Edições Câmara, 2012. 73 p. - (Série legislação; n. 81)

BRASIL, A lei dos Crimes Ambientais. Lei no 9.605 de 12 de fevereiro de 1998. Brasília, DF: Congresso Nacional. Disponível em: <http://www.planalto.gov.br/ccivil_03/LEIS/ L9605.htm> Acesso em 26 de março de 2014.

BRASIL. Política Nacional do Saneamento Básico. Lei 11.445 de 05 de janeiro de 2007. Brasília, DF: Congresso Nacional. Disponível em: <http://www.planalto.gov.br/ ccivil_03/_ato2007-2010/2007/lei/111445.htm> Acesso em 26 de março de 2014.

BRASIL, Política Nacional do Meio Ambiente. Lei no 6.938 de 31 de agosto de 1981. Brasília, DF: Congresso Nacional. Disponível em: < http://www.planalto.gov.br/ ccivil_03/Leis/L6938.htm> Acesso em 26 de março de 2014.

BROLLO, M. J.; PRESSIONOTTI, M. M. N.; MARCHIORI FARIA; D. G. Políticas Públicas em Desastres Naturais no Brasil. In: BROLLO, M. J. (Org.). O Instituto Geológico na prevenção de desastres naturais. 1. ed. São Paulo: Instituto Geológico, 2009, p. 57-63.

CIDERSP -GO. Consórcio Intermunicipal de Desenvolvimento da Região do São Patrício- GO. Disponível em: <http://www.cidersp.go.gov.br/index. php?pg=menu1 $>$. Acesso em 02/10/2014.
CHRISTENSEN, T.H.; KJELDSEN, P. Basic biochemical processes in landfills. In: Sanitary Landfilling: Process, Technology and Environimental Impact. CHRISTENSEN, T.H.; COSSU, R.; STEGMANN, R. (eds.). Academic Press, London, UK, p.29, 1989, Cap. 2.1

CORDEIRO, Cícera Josevânia Daniel; PEREIRA, Pedro Silvino; DUARTE, Antônia Eliene; BARROS Luiz Marivando; SOUZA, Marlene Menezes de. Prejuízos causados aos catadores que trabalham no lixão do município de Juazeiro do Norte - CE. Enciclopédia Biosfera, Centro Científico Conhecer, Goiânia, v.8, n.15; p.2553 - 2562. 2012.

DIAS, Divanita Cândida da Silva. Estratégia para gerenciamento de resíduos sólidos urbanos no município de Piracanjuba (GO). Dissertação (Mestrado) - Pontifícia Universidade Católica de Goiás, Programa de Pós-Graduação em Ecologia e Produção Sustentável, Goiânia: 2010. 146 f.

CALIXTO, B runo, Congresso quer adiar o fim dos lixões para 2021. ÉPOCA, 2015. Disponível em:<http://epoca. globo.com/colunas-e-blogs/blog-do-planeta/noticia/2015/07/ lixao-que-nao-acaba-mais.html> Acesso em: 25 de setembro de 2015.

CONAMA - Resolução CONAMA no 404, de 11 de novembro de 2008. Estabelece critérios e diretrizes para o licenciamento ambiental de aterro sanitário de pequeno porte de resíduos sólidos urbanos . <http:// www.mma.gov.br/port/conama/legislacao/CONAMA_RES CONS_2008_404.pdf>. Acesso em 15 jun. 2014.

DEMAJOROVIC, J.; BENSEN, G.R.; RATHSAM, A. A. Os desafios da gestão compartilhada de resíduos sólidos face à lógica do mercado. Disponível em: $<\mathrm{http}: / /$ www.anppas.org.br/encontro_anual/encontro2/GT/GT11/ jacuqes_demajorovic.pdf $>$. Acesso em 15 jun. 2015.

FERRI, Giovane Lopes, CHAVES, Gisele de Lorena Diniz, RIBEIRO, Glaydston Mattos. Análise e localização de centros de armazenamento e triagem de resíduos sólidos urbanos para a rede de logística reversa: um estudo de caso no município de São Mateus, ES. Production, v. 25, n. 1, p. 27-42, jan./mar. 2015.

GIL, A. C. Como elaborar projeto de pesquisa. $4^{\circ} \mathrm{ed}$. São Paulo. Atlas S. A, 1999.

IBGE - Instituto Brasileiro de Geografia e Estatística. Pesquisa Nacional por Amostra de Domicílios. Disponível em: < http://www.ibge.gov.br/home/estatistica/ populacao/trabalhoerendimento/pnad2008/>. Acesso em 23 maio de 2014>. 
IBGE - Instituto Brasileiro de Geografia e Estatística. Censo 2010. Disponível em: $<$ http://censo2010.ibge.gov. br/>. Acesso em: 24 de agosto de 2015.

IBGE - Instituto Brasileiro de Geografia e Estatística. IBGE Cidades. Disponível em: <http://cidades.ibge. gov.br/xtras/perfil.php?lang=\&codmun=522170\&searc $\mathrm{h}=$ goias $\mid$ uruana $\mid$ infograficos:-informacoes-completas $>$. Acesso em: 24 de setembro de 2015.

JOHNSTONE, N.; LABONNE, J. Generation of household solid waste in OCDE Countries: na empirical analysis using macroeconomic data. Land Economics, v. 80, n. 4, 2004 .

KÄMPF, N.; SCHNEIDER, P.; GIASSON, E. Propriedades, pedogênese e classificação de solos construídos em áreas de mineração na bacia carbonífera do baixo Jacuí (RS). Revista Brasileira de Ciência do Solo, v.21, p.79-88, 1997.

ABNT NBR 10.004/04 - Norma Brasileira - Disponível em: $<$ https: $/ /$ www.abntcatalogo.com.br/norma.aspx?ID=936>. Acesso em 04 de agosto de 2014.

MARQUES, Rosângela Francisca de Paula Vitor; SILVA, Antônio Marciano da; RODRIGUES, Luciano dos Santos e COELHO, Gilberto. Impactos da disposição de resíduos sólidos urbanos na qualidade da água superficial em três municípios de Minas Gerais - Brasil. Ciênc. agrotec. [online]. 2012, vol.36, n.6, pp. 684-692.

MMA - Ministério do Meio Ambiente. Política de Resíduos Sólidos apresenta resultados em 4 anos. Disponível em: <http://www.mma.gov.br/informma/item/10272pol\%C3\%ADtica-de-res\%C3\%ADduos-s\%C3\%B3lidosapresenta-resultados-em-4-anosD> Acesso em 20 de agosto de 2015.

PNUD - Programa das Nações Unidas para o Desenvolvimento. Disponível em:< http://www.pnud. org.br/IDH/DH.aspx> Acesso em 30 de agosto de 2015

SANEAGO, Saneamento de Goiás S.A. Disponível em: <http://www.saneago.com.br/ site/?id=programas $3 \&$ tit=programas $3>$ Acesso em: 24 de setembro de 2015.

SILVA, Rejane Moreira da. Saneamento Ambiental: Uma Análise do Quadro Recente em Goiás. Conjuntura econômica goiana, marco 2012 n 20. Disponível em: $<$ http://www.seplan.go.gov.br/sepin/pub/conj/conj20/artigo02. pdf $>$. Acesso em: 30 de marco de 2013.

WERTHEIN, J. Por Uma Nova Ética no Uso da Água. Jornal do Brasil, 25 de março de 2004 no, São Paulo 2p. 